\title{
A Case Study of Blended Teaching for Control Theory Course in Tsinghua University
}

\author{
Qianchuan Zhao, a , and Zhijin Cheng ${ }^{1, b}$ \\ ${ }^{1}$ Department of Automation and TNList, Tsinghua University, Beijing, 10084, China; \\ azhaoqc@tsinghua.edu.cn, bchengzj12@mails.tsinghua.edu.cn
}

Keywords: Blended teaching, face-to-face teaching, on-line teaching, pedagogical reform.

\begin{abstract}
This study aims to share the experiences of two instructors as they implement innovative methods (i.e., blended teaching approach) in teaching control theory in Tsinghua University. Group learning, students' mutual teaching, incentive mechanisms, and online courses are designed to improve the teaching performances. This blended teaching approach has been carried out among graduate students in four semesters. Some data including students' interviews, learning behaviors and study situations have been collected and analyzed to support our study. The practical experiences and findings could be a guide to pedagogical reform of other engineering courses in future.
\end{abstract}

\section{Introduction}

With the development of Information Communication Technologies (ICTs), online courses have been introduced to complement the face-to-face components [1]. This blended approach of offline and online education has been studied by various researchers in recent years. Elliot Masie (2002) regarded blended teaching as "the use of two or more distinct methods of training" [2]. Compared with the traditional teaching methods, blended approaches have the advantages of increasing flexibility [3, 4, 5], enhancing learners' autonomy [6] and independent learning [5, 7], motivating students' engagement [8,9], and creating pedagogic richness and cost-effectiveness [3, 10]. There are various Massive Open Online Courses (MOOCs) and organizations serving for blended teaching and learning. By 2016, hundreds of countries in the world join in online courses of the big three organizations, i.e., Coursera, edX, and Udacity. In China, thousands of courses are open online and seventy millions of learners join in online courses.

However, the effective implementation of blended approaches is a complex process, especially when trying to carry out pedagogical reform rather than supplementing traditional education. The major challenge is how to adapt to the role changes, i.e., both instructors and students are required to adapt to the role changes from teacher-directed learning to self-directed learning. For students, they are required to increase self-autonomy and self-direction, learn more independently and confidently, interact more effectively online, and enhance their readiness to learn in a blended environment [11, 12]. For instructors, they are required to devote more time and efforts, enhance pedagogical foundation, adopt new ICTs into their teaching, and provide more direct support for students offline and online $[13,14,15]$. Moreover, adequate support of the school and government to the teachers and students are also important in practice $[5,16,17]$. In this paper, we proposed a new blended approach to address the aforementioned issues and challenges. Various techniques involving group learning, student mutual teaching, and incentive mechanisms were designed to improve the quality of face-to-face process. With the support of Tsinghua University and Xuetangx platform, we opened the course of control theory online and supplemented the face-to-face process.

\section{Methodology}

The presented blended approach has two parts: online course teaching and face-to-face teaching. To motivate students' self-direction and enhance their readiness to learn in a blended environment, some teaching techniques are introduced for both offline and online course study. 
Group learning. Students in the classroom are divided into 6 groups and each group contains one group leader and 3 5 members. The leader is responsible for contacting with teaching assistant, assigning the tasks, and pushing members to study. The benefits of this technique are (1) encourage participants to discuss the problem they confront, exchange each other's attitudes and experiences, and explore and clarify their views (2) develop the teamwork ability (3) help the participants who are lack of independent learning ability to adapt to the new blended learning environment.

Online course study. As depicted in Fig.1 (a), online course contains four parts: video, lectures, exercises, and forum. All knowledge points of the course are explained through a series of short videos. Given learners' behaviors and habits, each video is made no longer than 10 mins to grab attentions. Lectures are also provided for learners in the form of PowerPoint. To examine and evaluate the learning effect, learners are required to complete the corresponding exercises after watching each video. Moreover, each unit has a special forum for discussions, which provides a convenient online platform for learners to discuss the problem they confront, exchange their attitudes and experiences with others. Owing to these designs of online course, students could prepare, learn and review lessons in their independently study and have more efforts on the focal and difficult points in the face-to-face study. Also, some related data could be collected and analyzed more conveniently by the new ICTs, which could provide potential opportunities to discover the hidden knowledge about the teaching performance and learners' behaviors.

Face-to-face study. In this subsection, various techniques involving group learning, students' mutual teaching, and incentive mechanisms are designed to improve the quality of face-to-face study process. Depicted as Fig.1 (b), the offline process mainly has three important parts: group learning, instructor teaching and final exam. Before class, students are required to learn the lessons online, which could leave more time for students to study the focal and discuss the difficulties. At the beginning, a group will be selected to give the lesson they learned online. Other groups will give their evaluations and ask the questions if they have. The instructor will give a comment to the group, complement the knowledge point, emphasize the key points and guide students to discuss the difficulties. To encourage students' readiness in the blended learning, evaluations of giving lessons and engagements in discussions will be regarded as a reward for their final scores. To complement the group learning, final exam is also set to encourage every student to work hard in the group.

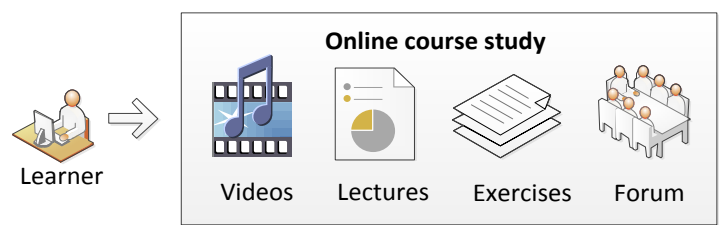

(a) Online course study

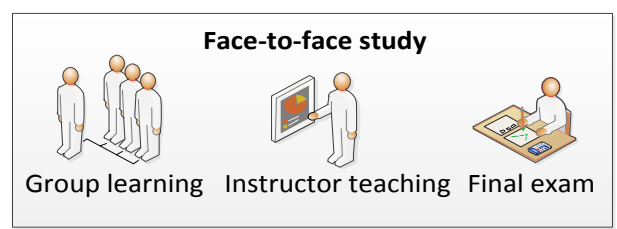

(b) Face-to-face study

Fig. 1 A schematic of blended study

The performance evaluation. A good design of performance evaluation is crucial for the quality of blended teaching in practice. In our approach, the final grade includes three parts: online course grade $(30 \%)$, group study course $(30 \%)$ and final exams $(40 \%)$, where group study course includes the evaluation of giving lessons and engagements in discussions. This design could encourage students to participate in the blended learning environment.

\section{Data analysis}

The data collected includes students' learning statistics and behaviors in the learning process, and interviews after class.

Students' study situations. Due to the online platform, some data involving students' learning statistics and behaviors could be easily collected and analyzed to improve the quality of blended teaching. Depicted as Fig.2, students' learning situations could be observed by students' score 
distribution and knowledge difficulty discovered. With these data, instructors could effectively allocate time and energy to meet students' real demands.

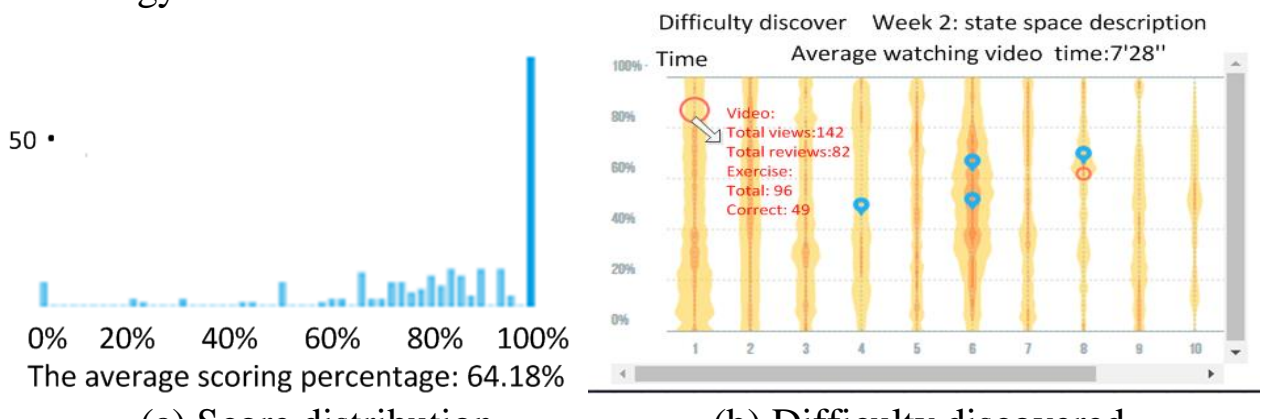

(a) Score distribution

(b) Difficulty discovered

Fig. 2 Students' learning statistics

Students' learning behaviors. Fig.3 demonstrates the analysis involving students' learning behaviors, where subfigure (a) shows students' learning custom and subfigure (b) indicates the relationships of students and instructors (or TA). The information about students' learning custom could direct instructors and teaching assistants to select right time online. The relationships in discussions could indicate the information of the students who are more active online. These information could make managers (i.e., instructors and TA) have opportunities to provide a personalized service for the learners.

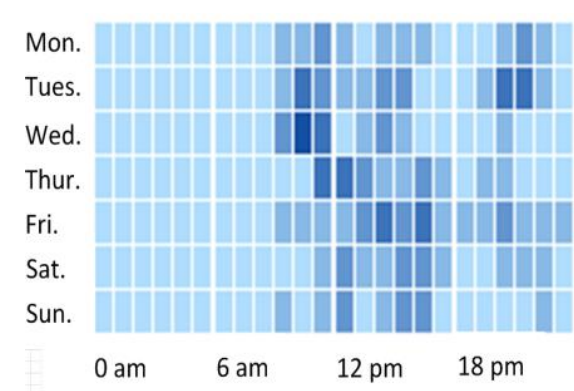

(a) Learning custom

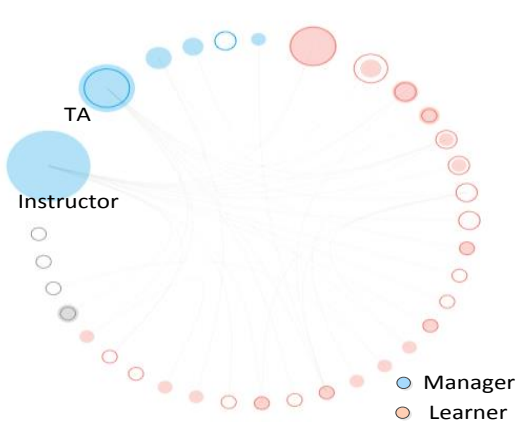

(b) Relationships in discussions

Fig. 3 Students' learning behaviors

Students' interviews. After the course, all 6 groups of students were made interviews about the evaluations of this blended teaching experience. Most students preferred the blended teaching approach since they have more chances to manage their time, make self-directed learning plan, raise their learning efficiency, exchange their views, and participant in the teamwork. The potential challenges are (1) Instructors should devote more time and energy for preparing and designing the course study. (2) Instructors should have enough capability to control the class.

\section{Summary}

This study shares the experiences of a blended teaching approach applied for control theory in Tsinghua University. Group learning, students' mutual teaching, and incentive mechanisms are introduced to improve the quality of face-to-face teaching. Short videos, exercises and forum could be good alternatives of the tools to enhance students' self-directed study online. This work could be a guide to pedagogical reforms of other engineering courses being implemented in practice. It indicates that more time, energy, teaching faculty and social support are required for instructors in blended teaching. Future work includes the comparison experiments between face-to-face teaching and blended teaching. 


\section{Acknowledgement}

This work was supported by Online Education Office, Tsinghua University, National 111 International Collaboration Project (B06002). The authors would like to thank Xuetangx for the support of online course and data analysis.

\section{References}

[1] P. Redmond, From face-to-face teaching to online teaching: Pedagogical transitions, Proc. of 28th Annual Conference of the Australasian Society for Computers in Learning in Tertiary Education: Changing Demands, Changing Directions. Australasian Society for Computers in Learning in Tertiary Education, (2011) 1050-1060.

[2] E. Masie, Blended learning: The magic is in the mix, The ASTD e-learning handbook, (2002) 58-63.

[3] C.J. Bonk, C.R. Graham, The Handbook of Blended Learning: Global Perspectives, Local Designs, John Wiley \& Sons, 2006.

[4] K. Pratt, A. Trewern, Students' experiences of flexible learning options: What can they tell us about what they need for success, Computers in New Zealand Schools: Learning, leading, technology, 23(2011).

[5] S. Parkes, P. Zaka, N. Davis, The first blended or hybrid online course in a New Zealand secondary school: A case study, Computers in New Zealand Schools: Learning, Teaching, Technology, 23(2011) 1-30.

[6] R. Reynard, Hybrid learning: Challenges for teachers, The Journal, 2007.

[7] R. Bolstad, M. Lin, Students' experiences of learning in virtual classrooms, Wellington, New Zealand: NZCER, 2009.

[8] M.K. Barbour, T.C. Reeves, The reality of virtual schools: A review of the literature, Computers \& Education, 52(2009) 402-416.

[9] S.K. Wang, T.C. Reeves, The effects of a web-based learning environment on student motivation in a high school earth science course, Educational technology research and development, 55(2007) 169-192.

[10] A. Powell, M. Barbour, Tracing international differences in online learning development: An examination of government policies in New Zealand, 2011.

[11] N. Wright, e-Learning and implications for New Zealand schools: A literature review, Ministry of Education, 2010.

[12] L.M. O'dwyer, R. Carey, G. Kleiman, A study of the effectiveness of the Louisiana Algebra I online course, Journal of research on technology in education, 39(2007) 289-306.

[13] D.M. Mupinga, Distance education in high schools: Benefits, challenges and suggestions, The Clearing House, 78(2005) 105-108.

[14] J.D. Klein, Instructor competencies: Standards for face-to-face, online, and blended settings, IAP, 2004.

[15] K. Kim, C.J. Bonk, Y. Teng, The present state and future trends of blended learning in workplace learning settings across five countries, Asia Pacific Education Review, 10(2009) 299-308.

[16] K.T. Lee, Online learning in primary schools: Designing for school culture change, Educational Media International, 43(2006) 91-106.

[17] K.M. Stevens, The distribution of instructional leadership in e-learning clusters: An ecological perspective, Unpublished master's thesis, University of Canterbury, Christchurch, New Zealand, 2011. 